\title{
A multiplex real-time PCR assay targeting virulence and resistance genes in Salmonella enterica serotype Typhimurium
}

\author{
Marie Bugarel', Sophie A Granier ${ }^{1}$, François-Xavier Weill ${ }^{2}$, Patrick Fach ${ }^{1}$ and Anne Brisabois ${ }^{*}$
}

\begin{abstract}
Background: Typhimurium is the main serotype of Salmonella enterica subsp. enterica implicated in food-borne diseases worldwide. This study aimed to detect the prevalence of ten markers combined in a macro-array based on multiplex real-time PCR. We targeted characteristic determinants located on pathogenicity islands (SPI-2 to -5 , virulence plasmid pSLT and Salmonella genomic island 1 (SGI1)) as well as a specific 16S-23S rRNA intergenic spacer sequence of definitive type 104 (DT104). To investigate antimicrobial resistance, the study also targeted the presence of genes involved in sulfonamide (sul1) and beta-lactam (b/a TEM) resistance. Finally, the int/1 determinant encoding integrase from class 1 integron was also investigated.

Results: A total of 538 unrelated S. Typhimurium strains isolated between 1999 and 2009 from various sources, including food animals, food products, human and environmental samples were studied. Based on the combined presence or absence of these markers, we distinguished 34 different genotypes, including three major genotypes encountered in $75 \%$ of the studied strains, Although SPI determinants were almost always detected, SGI1, intl1, sul1 and bla $a_{\text {TEM }}$ determinants were found $47 \%, 52 \%, 54 \%$ and $12 \%$ of the time respectively, varying according to isolation source. Low-marker patterns were most often detected in poultry sources whereas full-marker patterns were observed in pig, cattle and human sources.

Conclusion: The GeneDisc ${ }^{\circledR}$ assay developed in this study madeit easier to explore variability within serotype Typhimurium by analyzing ten relevant gene determinants in a large collection of strains. This real-time multiplex method constitutes a valuable tool for strains characterization on epidemiological purposes.
\end{abstract}

\section{Background}

Non-typhoid salmonellosis is one of the most frequently-reported bacterial foodborne diseases and is a major economic and public health issue worldwide. European data show that Salmonella is the second most predominant bacterial pathogen, causing around 132,000 human cases in 2008 [1]. In the United States, Salmonella serotypes cause an estimated 1.4 million cases of foodborne disease each year [2]. The primary reservoirs of Salmonella are food-producing animals, the three main sources being poultry, cattle and pigs. Of the numerous different serotypes, only a few are frequently

\footnotetext{
* Correspondence: anne.brisabois@anses.fr

${ }^{1}$ French Agency for Food, Environmental and Occupational Health Safety (ANSES) Laboratory for Food Safety, 23 Avenue du Général de Gaulle, F94706 Maisons-Alfort Cedex, France Full list of author information is available at the end of the article
}

isolated from human and animal sources. Serotypes Enteritidis and Typhimurium are the most frequently encountered in human and animal sources. Together, they represent $80 \%$ of confirmed human salmonellosis cases in Europe, with a marked decrease in serotype Enteritidis cases but an increase in $S$. Typhimurium cases [1]. Serotype Typhimurium was implicated in $47 \%$ of the notified foodborne outbreaks in France in 2008 http://www.invs.sante.fr. Of non-human isolates, this has been the most commonly-reported serotype in the French Salmonella network in its 15 years of surveillance. Furthermore, in many countries, definitive phage type 104 (DT104) has increased among serotype Typhimurium in the two past decades. Identifying Typhimurium phage types requires maintaining a phage library and specially trained personnel. There is thus a real need, therefore, to develop alternative molecular
C Biomed Central 
approaches for identifying Typhimurium DT104 strains. A DNA sequence unique to the DT104 phage type has already been described (16S-23S intergenic spacer sequence) $[3,4]$. Molecular analysis using relevant gene markers can improve the surveillance and typing of this well-isolated serotype. Markers selected in this study were especially related to virulence and antimicrobial resistance. Salmonella pathogenicity is based on the presence of various mobile elements. Five Salmonella pathogenicity islands (SPIs) are known to be involved in the virulence expression and invasivity of Salmonella [5]. SPI genes encode various functional proteins implicated in cellular invasion and the interaction between host and bacterial cells, such as the type III secretion system and effector proteins. In this study, the presence of four SPIs was investigated by targeting their gene determinants: the $s s a Q$ gene implicated in the secretion system apparatus protein (SPI-2), the $m g t C$ gene encoding the intramacrophage survival protein for SPI-3, the spi4D gene encoding HLYD family secretion protein for SPI-4 and the $\operatorname{sop} B$ gene implicated in the translocated effector protein of T3SS for SPI-5. The diversity of the Salmonella genome is related to the acquisition of plasmids that confer a selective advantage via antimicrobial resistance and/or virulence expression [6]. The common feature of Salmonella virulence plasmid loci is a wellconserved $7.8 \mathrm{~kb}$ region that plays a major role in the expression of the virulence phenotype in Salmonella. This $s p v$-locus may be present in serotype Typhimurium isolates and was tested by targeting the $s p v C$ gene.

Salmonella genomic island SGI1 is a $43 \mathrm{~kb}$ integrative mobilizable element that confers multidrug resistance and may also be involved in the increased virulence and invasivity of Salmonella Typhimurium DT104 strains. SGI1 has also been described in other serotypes, possibly acquired by horizontal transfer [7]. In this study, the presence of SGI1 was investigated by targeting the left junction in the flanking region of SGI1[8]. SGI1 harbors a cluster of genes containing the complex class 1 integron that encodes multidrug resistance, most often associated with the ACSSuT pentaresistance to amoxicillin (bla $\left.a_{\mathrm{PSE}-1}\right)$, chloramphenicol/florfenicol (floR), streptomycin/spectinomycin (aadA2), sulfonamide (sul1) and tetracycline (tet $G$ ). The 5' well-conserved region including the intI1 determinant that encodes integrase from class 1 integron was targeted, as was the sull gene that codes for resistance to sulphonamides. Antimicrobial resistance to beta-lactams has also been reported in isolates from human and animal sources (6). Resistance mechanisms such as penicillinase hyperproduction, extended spectrum beta-lactamases (ESBL) or inhibitor-resistant TEM beta-lactamase are encoded by the plasmidmediated $b l a_{\text {TEM }}$ gene. The presence and diffusion of $b l a_{\text {TEM }}$ genes are a serious public health issue, and could be responsible of treatment failure.

The aim of this work was to develop a simple, easy-touse tool for Salmonella genotyping based on the detection of genes of significant public health concern. The macroarray-based assay was applied to a large collection of serotype Typhimurium isolates representative of various sources and sampled at different times over a 10year period.

\section{Methods}

\section{Principle of the GeneDisc ${ }^{\circledR}$ array}

The principle of the GeneDisc ${ }^{\circledR}$ array (GeneSystems, Bruz, France, http://www.genesystems.fr) has been described previously [9]. It is a disposable plastic tray the size of a compact disc. Its rim is engraved with 36 reaction microchambers preloaded with desiccated primers and fluorescence-labeled probes for target detection. The GeneDisc ${ }^{\circledR}$ is divided into six sectors, each linked to six microchambers. A duplex real-time PCR can be performed in each microchamber using reporter dye 6-FAM (490-520 nm) or ROX (580-620 nm). Each GeneDisc $^{\circledR}$ can be used to simultaneously investigate six strains in order to detect 12 markers. The 40 -cycle thermal PCR program takes 45 minutes. Results are recorded and can also be followed in real time on the computer screen. GeneSystems' GeneDisc ${ }^{\circledR}$ system has been recently used to genotype verotoxin-producing Escherichia coli [10].

\section{GeneDisc $^{\circledR}$ array developed in this study}

The GeneDisc ${ }^{\circledR}$ array was designed to simultaneously detect 10 specific gene targets, together with a negative control and a positive Salmonella genus control (trC gene previously described) [11]. This "STM GeneDisc ${ }^{\circledR}$ " array was set up as follows: microwell 1) intI1 (6-FAM label) and $\operatorname{sop} B$ (ROX-label); microwell 2) bla $a_{\mathrm{TEM}}$ (FAM) and ssaQ (ROX); microwell 3) spvC (FAM) and spi_4D (ROX), microwell 4) DT104 16S to 23S spacer (FAM) and mgtC (ROX); microwell 5) ttrC gene (FAM) and sul1 (ROX); and microwell 6) SGI1 left junction (FAM) and negative control (ROX). The oligonucleotide primers and gene probes used in the GeneDisc ${ }^{\circledR}$ are given in Table 1. All the oligonucleotides were purchased from Sigma-Aldrich (St. Quentin Fallavier, France). GeneSystems (Bruz, France) was responsible for GeneDisc ${ }^{\circledR}$ spotting and manufacturing. All the gene markers are detected with the GeneDisc ${ }^{\mathbb{B}}$ system in less than one hour of operation.

\section{Bacterial strains}

A total of 538 isolates selected from 8,663 serotype Typhimurium isolates from the French Food Safety 
Table 1 Primers and probes designed for the GeneDisc ${ }^{\circledR}$ assay

\begin{tabular}{|c|c|c|c|}
\hline Target sequence & Forward primer, reverse primer and probe sequences $\left(5^{\prime}-3^{\prime}\right)$ & GenBank accession number & Location within sequence \\
\hline DT104 & GGACCTGGCTGAGTTATTTCG & & $1370-1391$ \\
\hline $16 S-23 S$ & GCATCGGCTGTGAGACCAA* & AF275268 & $1438-1420$ \\
\hline \multirow[t]{2}{*}{ spacer $^{\mathrm{a}}$} & FAM-TGGTTTCTGAAAGCGGAGCTAATGCG-BHQ & & $1393-1418$ \\
\hline & TCTGCTGAGCGACAACAGATTT & & $1498146-1498167$ \\
\hline \multirow[t]{3}{*}{$s s a Q^{b}$} & TGGCACCAGCCTGAATATACAG* & AE006468 & $1498213-1498192$ \\
\hline & ROX-TCCTGCCCCTCCTGTGGTAGT -BHQ & & $1498169-1498189$ \\
\hline & AAGAGGCCGCGATCTGTTTA* & & $3964669-3964650$ \\
\hline \multirow[t]{3}{*}{$m g t C^{c}$} & CGAATTTCTITATAGCCCTGTTCCT & AE006468 & $3964600-3964624$ \\
\hline & ROX-AAGGGTTAGGTTCGGTCCCCG-BHQ * & & $3964648-3964628$ \\
\hline & CGGCGGACTTACTIITTGAAA & & $4482051-4482071$ \\
\hline \multirow[t]{3}{*}{ spi4_D $D^{d}$} & TGGTCACGGTATTTGGGTAATATTT* & AE006468 & $4482132-4482108$ \\
\hline & ROX-CCAAAAGTAAGGACTATGCTGGCCG-BHQ & & $4482077-4482101$ \\
\hline & CTTATGAGGGAAAGGGCG* & & $1179300-1179283$ \\
\hline \multirow[t]{3}{*}{$s o p B^{e}$} & ATGCACACTCACCGTGG & AE006468 & $1179215-1179231$ \\
\hline & ROX-TTGGGATACCAAGAATATTCATCACGCC-BHQ* & & $1179275-1179248$ \\
\hline & AATGAACTACGAAGTGGGCG* & & $24307-24288$ \\
\hline \multirow[t]{3}{*}{ spve } & TCAAACGATAAAACGGTTCCTC & FN432031 & $24232-24253$ \\
\hline & FAM-ATGGTGGCGAAATGCAGAGACAGGC -BHQ* & & $24285-24261$ \\
\hline & GGATTTTCTCCAGCTTCTGT & & $132-151$ \\
\hline \multirow[t]{3}{*}{ Left junction of $\mathrm{SGl} 1^{\mathrm{g}}$} & CTAACCATAAGAGAACTTCC* ${ }^{*}$ & AF261825 & $263-244$ \\
\hline & FAM-TAAATCTCCTAAATTAAATTAAAACGAAGTAAAACC -BHQ & & $161-197$ \\
\hline & TGGGCAGCAGCGAAGTC* & & $27686-27670$ \\
\hline \multirow[t]{3}{*}{ int $/ 7^{\mathrm{h}}$} & TGCGTGGAGACCGAAACC & AF261825 & $27617-27634$ \\
\hline & FAM-AGGCATTTCTGTCCTGGCTGGCG-BHQ* & & $27668-27646$ \\
\hline & CTGGATCTCAACAGCGG & & $270-286$ \\
\hline \multirow[t]{3}{*}{ bla ${ }_{\text {TEM }}{ }^{\prime}$} & CAACACGGGATAATACCGC* & AJ634602 & $378-360$ \\
\hline & FAM- AGATCCTTGAGAGTITTCGCCCCG-BHQ & & $289-312$ \\
\hline & TCCTGACCCTGCGCTCTATC & & $29611-29630$ \\
\hline \multirow[t]{2}{*}{ sult ${ }^{\mathrm{j}}$} & TGCGCTGAGTGCATAACCA* & AF261825 & $29679-29661$ \\
\hline & ROX-ATTGCTGAGGCGGACTGCAGGC -BHQ & & $29636-29657$ \\
\hline
\end{tabular}

FAM = 6-carboxylfluorescein; ROX = carboxy-X-rhodamine; BHQ = Black Hole Quencher. ${ }^{*}$ complementary strand; ${ }^{a}$ :marker of the phage type DT104 located in the 16S-to-23S spacer region of bacterial rRNA genes [4]; ${ }^{b}$ : gene encoding SsaQ; ${ }^{c}$ : gene encoding MgtC; ${ }^{d}$ : gene encoding Spi4_D; ${ }^{\text {e }}$ gene encoding SopB; ${ }^{f}$ : gene encoding SpvC; ${ }^{9}$ : marker of the SGI1 left junction which is composed of the end of the thdF gene and the intergenic sequence between thdF and int genes [8]; ${ }^{h}$ : marker targeting the gene encoding the integrase of the class 1 integron inside SGI1; ${ }^{i}$ : gene encoding beta-lactam resistance; ${ }^{j}$ :gene encoding sulphonamide resistance.

Agency (AFSSA, Maisons-Alfort, France) collection were analyzed. They were isolated between 1999 and 2009 in France and identified as Salmonella enterica enterica serotype Typhimurium according to the White-Kauffmann-Le Minor scheme by agglutination with $\mathrm{O}$ - and $\mathrm{H}$-antigen specific sera (BioRad, Marnes-la-Coquette, France). The Salmonella isolates are sent on a voluntary basis through a network 150 veterinary or food analysis laboratories covering different French districts. Sampling was carried out firstly to remove duplicate strains and to select different sources of isolation and secondly on a random basis. The selected isolates can be considered representative of the total collection of the Salmonella network. Thus, for each year, at least one representative isolate from the three main sectors-animals, food or the environment (natural environment or ecosystem)-was tested. Within each sector, we then selected strains from various food-animal sources (poultry, swine and cattle) including primary production sites, livestock farms and raw materials from processing sites or from domestic or wild species. As described in Table 2, isolates were from samples of pigs $(n=61)$, poultry $(n=212)$, cattle $(n=$ 67 ) and from other minor domestic or wild animal species $(n=51)$. The latter included strains from birds $(n=$ $11)$, sheep $(n=9)$, horses $(n=6)$, goats $(n=5)$, snakes $(\mathrm{n}=2)$ and rabbits $(\mathrm{n}=2)$. We also investigated strains isolated from the environment $(\mathrm{n}=23)$ and food products $(\mathrm{n}=90)$, including ready-to-eat foods $(\mathrm{n}=16)$, pork $(n=28)$, dairy products $(n=14)$, beef $(n=6)$, seafood $(n=5)$, egg products $(n=5)$ and vegetables $(n=$ 
Table 2 Genotype distribution according to isolation sources

\begin{tabular}{|c|c|c|c|c|c|c|c|c|c|}
\hline \multirow[b]{2}{*}{ Genotype } & \multicolumn{5}{|c|}{ Food Animal sources } & \multirow[b]{2}{*}{ Food products ${ }^{2}$} & \multirow[b]{2}{*}{ Human } & \multirow[b]{2}{*}{ Environment } & \multirow[b]{2}{*}{ Unknown } \\
\hline & No. & Pigs & Poultry & Cattle & Other species $^{1}$ & & & & \\
\hline $\mathrm{A} 1$ & 1 & & & 1 & & & & & \\
\hline $\mathrm{A} 2$ & 3 & 1 & 1 & & 1 & & & & \\
\hline $\mathrm{A} 3$ & 3 & & 2 & & & 1 & & & \\
\hline A4 & 1 & & & 1 & & & & & \\
\hline A5 & 145 & 4 & 84 & 12 & 17 & 16 & 4 & 5 & 3 \\
\hline A6 & 1 & & 1 & & & & & & \\
\hline A7 & 3 & & 1 & 1 & & 1 & & & \\
\hline A8 & 2 & & & & 1 & 1 & & & \\
\hline A9 & 53 & 5 & 25 & 5 & 6 & 10 & 1 & & 1 \\
\hline B1 & 6 & 1 & 1 & & 2 & 1 & & 1 & \\
\hline B2 & 19 & 1 & 10 & 1 & 2 & 4 & & 1 & \\
\hline B3 & 9 & 1 & 1 & 2 & 3 & & 2 & & \\
\hline B4 & 1 & 1 & & & & & & & \\
\hline B5 & 2 & & & 1 & 1 & & & & \\
\hline B6 & 210 & 39 & 60 & 38 & 12 & 38 & 11 & 12 & \\
\hline B7 & 3 & 1 & 1 & & & 1 & & & \\
\hline B8 & 8 & & 1 & 2 & & & 5 & & \\
\hline B9 & 6 & 1 & 2 & 1 & & 1 & & & 1 \\
\hline B10 & 2 & & 1 & & & 1 & & & \\
\hline B11 & 1 & & 1 & & & & & & \\
\hline B12 & 2 & & & 1 & & 1 & & & \\
\hline B13 & 4 & & 4 & & & & & & \\
\hline B14 & 2 & & & 1 & 1 & & & & \\
\hline B15 & 1 & & & & 1 & & & & \\
\hline $\mathrm{C} 1$ & 1 & 1 & & & & & & & \\
\hline $\mathrm{C} 2$ & 21 & 4 & 7 & & 1 & 6 & 1 & 1 & 1 \\
\hline C3 & 1 & & 1 & & & & & & \\
\hline C4 & 10 & 1 & 5 & & 1 & 1 & 2 & & \\
\hline C5 & 1 & & & & & 1 & & & \\
\hline C6 & 5 & & & & 2 & 2 & 1 & & \\
\hline C7 & 2 & & 2 & & & & & & \\
\hline $\mathrm{C} 8$ & 7 & & 1 & & & 4 & 1 & 1 & \\
\hline$D$ & 1 & & & & & & & 1 & \\
\hline$E$ & 1 & & & & & & & 1 & \\
\hline Total & 538 & 61 & 212 & 67 & 51 & 90 & 28 & 23 & 6 \\
\hline
\end{tabular}

${ }^{1}$ Birds (11), Sheep $(N=9)$, Horses $(N=6)$, Goats $(N=5)$, Snakes (2), Rabbits (2), Unknown (16).

${ }^{2}$ Cooked dishes (16), Pork (28), Diary products (14), Beef (6), Seafood (5), Egg products (5), Vegetables (3), Unknown (13).

3). Analyses were also conducted on a panel of few clinical human Salmonella Typhimurium isolates $(\mathrm{n}=28)$ collected by the National Reference Centre for Salmonella (Institut Pasteur, Paris) and selected according to their various sources and PFGE genetic diversity.

A set of control strains was used to validate the STM GeneDisc $^{\circledR}$ array (Table 3). Reference strain LT2 was used as a positive control for testing SPI genetic markers (ssaQ, $m g t C$, spi4- $D$ and sopB genes), and virulence plasmid pSLT $(s p v C$ gene). Typhimurium strain 08CEB5766SAL was used as a negative control for testing the $s s a Q, \operatorname{sop} B$ and $s p v C$ markers, whereas the 00-
01041 strain kindly provided by the Federal Institute for Risk Assessment (BfR) in Berlin, Germany, was used as a negative template to test the spi4_D and mgtC markers. All these negative control strains had been tested previously using conventional PCR.

The specificity of the phage type DT104 marker targeting the 16S-23S rRNA intergenic spacer region was tested with 43 strains of different phage types: atypical DT146 ( $\mathrm{n}=1)$, DT120 ( $=10)$, DT135 ( $\mathrm{n}=1)$, DT99 $(\mathrm{n}=1)$, DT8 $(\mathrm{n}=2)$, DT193 $(\mathrm{n}=4)$, DT30 $(\mathrm{n}=2)$, DT12 $(\mathrm{n}=2)$, DT4 variant $(\mathrm{n}=1)$, U302 $(\mathrm{n}=12)$, DT2 $(\mathrm{n}=1)$, DT208 $(\mathrm{n}=1)$, DT12a $(\mathrm{n}=1)$, DT136 $(\mathrm{n}=1)$, 
Table 3 Set of control strains

\begin{tabular}{|c|c|c|c|c|c|c|c|c|c|c|c|}
\hline Strain & Source & DT104 16S- 23S spacer & ssaQ & mgtC & spi4_D & sop $B$ & spvC & SGI1 left Junction & int/1 & $b l a_{\mathrm{TEM}}$ & sul1 \\
\hline $\mathrm{LT} 2$ & & - & + & + & + & + & + & - & - & - & - \\
\hline 05CEB1571SAL & ANSES & + & + & + & + & + & + & + & + & - & - \\
\hline 07CEB5289SAL & ANSES & - & + & + & + & + & - & - & + & + & + \\
\hline 07CEB9150SAL & ANSES & + & + & + & + & + & - & - & - & + & - \\
\hline 01CEB12158 & ANSES & - & + & + & + & + & - & - & - & - & - \\
\hline 08CEB5766SAL & ANSES & + & - & + & + & - & - & - & - & - & - \\
\hline 63.48 & DTU Food & + & + & + & + & + & - & - & - & + & - \\
\hline 61.12 & DTU Food & - & + & + & + & + & - & - & + & + & + \\
\hline 00-01041 & BfR & & & - & - & & & & & & \\
\hline
\end{tabular}

DT18 ( $\mathrm{n}=1)$, DT36 ( $\mathrm{n}=1), \mathrm{U} 311(\mathrm{n}=1)$ and 59 strains of phage type DT104.

Phage-typing had already been performed either in the Laboratory of Gastrointestinal Pathogens at the Health Protection Agency (HPA, London, UK) or in the National Reference Centre on Salmonella at the Institut Pasteur (Paris, France). The presence of SGI1 was explored by targeting the left junction sequence and detecting integrase of class 1 integron gene (intI1) and a sulfonamide resistance determinant (sul1). The positive control strain used for these three markers was $S$. Typhimurium strain 05CEB1571SAL, a strain isolated from turkey and well-characterized by a European project. Positive results had already been detected for the left junction sequence, intI1 and sul1 genes. Finally, the study validated detection of the beta-lactam resistance gene $\left(b l a_{\mathrm{TEM}}\right)$ by testing ANSES and European collection strains 07CEB5289SAL of serotype Virchow, 07CEB9150SAL and 63.48 of serotype Paratyphi B var. Java, and 61.12 of serotype Isangii carrying respectively $b l a_{\mathrm{TEM}-1}$ (penicillinase-producing), bla $a_{\mathrm{TEM}-52}, b l a_{\mathrm{TEM}-20}$ and bla TEM-63 variants linked to ESBL phenotypes (Table 3).

For test purposes, bacteria were cultured from a single colony on agar plates and grown overnight at $37^{\circ} \mathrm{C}$. DNA from a small aliquot of the colony corresponding to approximately $2 \times 10^{6}$ bacteria was extracted using the InstaGene matrix (Bio-Rad Laboratories) and $36 \mu \mathrm{L}$ of the DNA extracts were tested using the STM Gene$\operatorname{Disc}^{\circledR}$ array.

\section{Data Analysis}

Results are based on reaction curves and other features of real-time PCR that can be analyzed and printed as tables with MS Excel (Microsoft). To normalize results, a maximum cycle threshold-indicating the PCR cycle th at shows a significant increase in the fluorescence signal compared to the background-and minimum fluorescence amplitude were defined at 30 cycles and 500 arbitrary fluorescence units respectively. All percentage values for each genetic marker were calculated with their confidence interval at $95 \%$ according to a FisherSnedecor distribution. For phage-type DT104 determination, the specificity calculation was the proportion of negative tests which are true negative. The sensitivity was the proportion of positive tests which are true positive.

The normalized presence or absence of each gene determinant for each strain was analyzed as character values using BioNumerics software version 5.1 (Applied Maths, Sint-Martens-Latem, Belgium). A cluster analysis was performed with the Dice coefficient using the unweighted pair group method with arithmetic averages (UPGMA dendrogram). Cluster analysis was used to define different groups of genotypes, the term "genotype" indicating strains with a similar gene determinant profile.

\section{Results}

Prevalence of gene determinants in serotype Typhimurium strains

-Virulence determinants

All the investigated strains carried the $\operatorname{tr} C$ marker specific to the Salmonella genus. The virulence potential of Typhimurium strains was characterized by testing five virulence-associated determinants. Four of them are located on SPI-2 to -5 and one, $s p v C$, is related to the Salmonella Typhimurium virulence plasmid (pSLT). Each marker was tested against one positive strain (LT2) and against a specific negative control. The efficiency of each marker was checked and validated. SPI determinants are well conserved and usually present in all Salmonella enterica strains because they were acquired during Salmonella evolution [7]. Nevertheless, in this study, some atypical strains $(n=5)$ were observed and tested negative for one or two SPI markers.

We found three strains that were negative for $s s a Q$, and a single strain negative for spi4_D or sopB. These results suggest that there has been deletion or changes in the SPI-2 and/or SPI-4 region. The mgtC marker was detected in all 538 tested strains, indicating that the SPI-3 region was always present, whatever the strain (Table 4). The $s p v C$ gene pSLT determinant was 
Table 4 Distribution of gene determinant among isolation sources

\begin{tabular}{|c|c|c|c|c|c|c|c|c|c|c|c|}
\hline \multirow[b]{2}{*}{ Sources } & \multirow[b]{2}{*}{ No. of isolates } & \multicolumn{10}{|c|}{ Percentage of gene determinant presence (confidence interval at 95\%) } \\
\hline & & DT104 16S-23S spacer & ssaQ & mgtC & spi4_D & sopB & $\operatorname{spvC}$ & SGI1 left junction & int/1 & $b l a_{\mathrm{TEM}}$ & sul1 \\
\hline Pigs & 61 & $\begin{array}{c}66 \\
(52.31-77.27)\end{array}$ & $\begin{array}{c}100 \\
(95.21-100)\end{array}$ & $\begin{array}{c}100 \\
(95.21-100)\end{array}$ & $\begin{array}{c}98 \\
(91.2-99.96)\end{array}$ & $\begin{array}{c}100 \\
(95.21-100)\end{array}$ & $\begin{array}{c}89 \\
(77.78-95.26)\end{array}$ & $\begin{array}{c}67 \\
(54-78.69)\end{array}$ & $\begin{array}{c}75 \\
(62.71-85.54)\end{array}$ & $\begin{array}{c}18 \\
(9.36-29.98)\end{array}$ & $\begin{array}{c}75 \\
(62.71-85.54)\end{array}$ \\
\hline Poultry & 212 & $\begin{array}{c}34 \\
(27.62-40.76)\end{array}$ & $\begin{array}{c}100 \\
(98.60-100)\end{array}$ & $\begin{array}{c}100 \\
(98.60-100)\end{array}$ & $\begin{array}{c}100 \\
(98.60-100)\end{array}$ & $\begin{array}{c}100 \\
(98.60-100)\end{array}$ & $\begin{array}{c}80 \\
(74.18-85.33)\end{array}$ & $\begin{array}{c}37 \\
(30.29-43.67)\end{array}$ & $\begin{array}{c}39 \\
(32.54-46.07)\end{array}$ & $\begin{array}{c}10 \\
(6.24-14-74)\end{array}$ & $\begin{array}{c}41 \\
(34.35-47.98)\end{array}$ \\
\hline Cattle & 67 & $\begin{array}{c}65 \\
(53.06-76.85)\end{array}$ & $\begin{array}{c}100 \\
(95.63-100)\end{array}$ & $\begin{array}{c}100 \\
(95.63-100)\end{array}$ & $\begin{array}{c}98 \\
(91.96-99.96)\end{array}$ & $\begin{array}{c}100 \\
(95.63-100)\end{array}$ & $\begin{array}{c}86 \\
(76.03-93.67)\end{array}$ & $\begin{array}{c}65 \\
(53.06-76.85)\end{array}$ & $\begin{array}{c}71 \\
(59.31-81.99)\end{array}$ & $\begin{array}{c}8 \\
(2.47-16.56)\end{array}$ & $\begin{array}{c}76 \\
(64.14-85.69)\end{array}$ \\
\hline Other animal species ${ }^{1}$ & 51 & $\begin{array}{c}31 \\
(24.13-51.92)\end{array}$ & $\begin{array}{c}98 \\
(89.55-99.95)\end{array}$ & $\begin{array}{c}100 \\
(94.3-100)\end{array}$ & $\begin{array}{c}98 \\
(89.55-99.95)\end{array}$ & $\begin{array}{c}100 \\
(94.3-100)\end{array}$ & $\begin{array}{c}82 \\
(69.13-91.6)\end{array}$ & $\begin{array}{c}31 \\
(19.11-45.89)\end{array}$ & $\begin{array}{c}43 \\
(29.35-57.75)\end{array}$ & $\begin{array}{c}12 \\
(4.44-23.87)\end{array}$ & $\begin{array}{c}47 \\
(32.93-61.54)\end{array}$ \\
\hline Food products ${ }^{2}$ & 90 & $\begin{array}{c}53 \\
(42.51-63.93)\end{array}$ & $\begin{array}{c}100 \\
(96.73-100)\end{array}$ & $\begin{array}{c}100 \\
(96.73-100)\end{array}$ & $\begin{array}{c}100 \\
(96.73-100)\end{array}$ & $\begin{array}{c}100 \\
(96.73-100)\end{array}$ & $\begin{array}{c}78 \\
(67.79-85.87)\end{array}$ & $\begin{array}{c}49 \\
(38.2-59.65)\end{array}$ & $\begin{array}{c}52 \\
(41.43-62.87)\end{array}$ & $\begin{array}{c}11 \\
(5.46-19.49)\end{array}$ & $\begin{array}{c}56 \\
(44.7-66.04)\end{array}$ \\
\hline Human & 28 & $\begin{array}{c}71 \\
(51.33-86.78)\end{array}$ & $\begin{array}{c}100 \\
(89.85-100)\end{array}$ & $\begin{array}{c}100 \\
(89.85-100)\end{array}$ & $\begin{array}{c}100 \\
(89.85-100)\end{array}$ & $\begin{array}{c}100 \\
(89.85-100)\end{array}$ & $\begin{array}{c}86 \\
(67.33-95.97)\end{array}$ & $\begin{array}{c}57 \\
(37.18-75.54)\end{array}$ & $\begin{array}{c}64 \\
(44.07-81.36)\end{array}$ & $\begin{array}{c}36 \\
(18.64-55.93)\end{array}$ & $\begin{array}{c}64 \\
(44.07-81.36)\end{array}$ \\
\hline Environment & 23 & $\begin{array}{c}61 \\
(38.54-80.29)\end{array}$ & $\begin{array}{c}96 \\
(78.05-99.89)\end{array}$ & $\begin{array}{c}100 \\
(87.79-100)\end{array}$ & $\begin{array}{c}100 \\
(87.79-100)\end{array}$ & $\begin{array}{c}96 \\
(78.05-99.89)\end{array}$ & $\begin{array}{c}91 \\
(71.96-98.93)\end{array}$ & $\begin{array}{c}61 \\
(38.54-80.29)\end{array}$ & $\begin{array}{c}61 \\
(38.54-80.29)\end{array}$ & $\begin{array}{c}9 \\
(1.07-28.04)\end{array}$ & $\begin{array}{c}65 \\
(42.73-83.62)\end{array}$ \\
\hline Unknown & 6 & $\begin{array}{c}0 \\
(0-39.3)\end{array}$ & $\begin{array}{c}100 \\
(60.7-100)\end{array}$ & $\begin{array}{c}100 \\
(60.7-100)\end{array}$ & $\begin{array}{c}100 \\
(60.7-100)\end{array}$ & $\begin{array}{c}100 \\
(60.7-100)\end{array}$ & $\begin{array}{c}67 \\
(22.28-95.67)\end{array}$ & $\begin{array}{c}0 \\
(0-39.3)\end{array}$ & $\begin{array}{c}17 \\
(0.42-64.12)\end{array}$ & $\begin{array}{c}33 \\
(4.22-77.72)\end{array}$ & $\begin{array}{c}17 \\
(0.42-64.12)\end{array}$ \\
\hline Total & 538 & 47 & 99 & 100 & 99 & 99 & 82 & 47 & 52 & 12 & 54 \\
\hline
\end{tabular}


frequently present (80 to 90\%) in the studied strains whatever their isolation source (Table 4). These results are consistent with a recent virulotyping study on a large European collection of Salmonella strains, where $s p v C$ was found only in serotype Typhimurium (68\%) and Enteritidis (85\%) among the five serotypes regulated in Europe [12]. In the same study, SPI-1 to -5 determinants were conserved in the five serotypes.

\section{-Salmonella genomic Island (SGI1) determinants}

The SGI1 structure was detected using the left junction region, the integrase of class 1 integron gene (intI1) and the sul1 resistance determinant located in the multidrug resistance region. The left junction sequence, intI1 and sul1 genetic markers are all closely associated with SGI1. Not surprisingly, the frequencies of each marker were similar. Nevertheless, some strains carrying intI1 and/or sul1 were negative for the left junction region. Moreover, a few sul1 positive strains were negative for intI1 and/or the left junction region. Such results could suggest these markers are plasmid-mediated.

\section{- Phage type DT104 determinant}

The phage type DT104 determinant was explored by targeting a 16S-23S rRNA intergenic spacer sequence. This sequence is considered to be specific to DT104 strains [4]. Positive and negative control strains were used for this marker. Of the 59 confirmed DT104 strains, all but four were positive. Furthermore, the sequence was not detected in the atypical DT146 ( $\mathrm{n}=$ $1)$ DT120 ( $n=1)$, DT135 ( $n=1)$, DT99 ( $\mathrm{n}=1)$, DT8 $(\mathrm{n}=2)$, DT193 $(\mathrm{n}=4)$, DT30 $(\mathrm{n}=3)$, DT12 $(\mathrm{n}=2)$, DT4 variant $(\mathrm{n}=1)$, U302 $(\mathrm{n}=12)$, DT2 $(\mathrm{n}=1)$, DT208 ( $\mathrm{n}=1)$, DT12a ( $=1)$, DT18 ( $=1)$, DT36 ( $=1)$ or U311 $(n=1)$ strains. However, we observe a cross-reaction with one DT136 strain and nine of the ten DT120 strains investigated out of the 102 strains tested. The specificity and sensitivity values for this gene target were of $89.5 \%$ and $84.6 \%$ respectively. The DT104 marker was detected in $47 \%$ of the 538 tested strains with unequal distribution among isolate sources. This marker was carried by $71 \%$ of human strains (Table 4 ). Furthermore, the DT104 marker was observed in around $60 \%$ of environmental samples. Nearly half the food product strains carried this marker, while the lowest frequencies occurred in poultry and other animal species, with around $40 \%$ of positive strains.

\section{- Antimicrobial resistance determinants}

Beta-lactam resistance including ESBL and non-ESBL producing strains was explored by targeting a family of $b l a_{\text {TEM }}$ genes encoding TEM beta-lactamase enzymes. Reference positive strains carrying $b l a_{\mathrm{TEM}-1}, b l a_{\mathrm{TEM}-20}$, $b l a_{\text {TEM-52 }}$ and $b l a_{\text {TEM-63 }}$ were correctly detected with the GeneDisc ${ }^{\circledR}$ array.

The bla $a_{\text {TEM }}$ determinant was unequally distributed among the tested strains. The highest level-36\%-was detected in human isolates. In animal or food sources, it was found in around 10 to $20 \%$ of strains (Table 4).

Sulfonamide resistance was detected by targeting the sul1 determinant, most often associated with the SGI1 gene cluster and phage type DT104 strains. sul1 rates varied according to isolation sources, the highest levels being found in swine (75\%) and bovine (74\%) isolates and the lowest in poultry (41\%) and other minor animal species (47\%).

\section{Assignment of Typhimurium genotypes}

All the strains were classified according to their genotype determined by the combination of the ten investigated markers. Using this combination of markers, the 538 strains were grouped into 34 different genotypes according to the UPGMA method. A dendrogram was generated using the Dice correlation coefficient. Genotypes were clustered into three main groups and two minor groups named A to E (Figure 1 and Table 2).

Group A was composed of 211 strains divided into nine profiles: A1 to A9. Some of them were relatively rare, whereas two were very frequently observed (A5 and A9 genotypes). Strains in this group were usually negative for the DT104 determinant (98\%) but positive for the sulfonamides resistance marker (sul1 gene). The class 1 integron marker (intI1) was never detected, though some Group A strains harbored the SGI1 determinant. Moreover, the beta-lactam resistance determinant TEM was present in three strains with A2 profiles. The major genotype A5 accounted for $67 \%$ of Group A strains and was linked to the presence of all four SPI determinants and the plasmid-associated $s p v C$ determinant. A second profile, A9, occurred more frequently than the others, accounting for $24 \%$ of Group A strains. A5 and A9 genotypes were very closely related as the A9 profile shared the A5 determinant profile, differing only by the absence of $s p v C$. Both profiles were encountered every year in strains from various sources (Figure 1 and Table 2). Group B was the largest, containing 276 strains. The 15 genotypes of Group B were distributed throughout the 10-year study period (1999-2009). The most common genotype was B6, detected in all types of sources and encountered in $76 \%$ of Group B strains $(\mathrm{n}=210)$. All determinants except the $b l a_{\text {TEM }}$ gene were positive in this genotype. The other 14 profiles were much less frequent (Table 2). Furthermore, $84 \%$ of Group B strains were positive for the DT104 marker. Group B strains consistently exhibited sul1 and intI1 determinants, whereas $88 \%$ of these strains $(n=244)$ carried the SGI1 left junction marker. As previously reported, the SGI1 left junction region was not conserved among all 


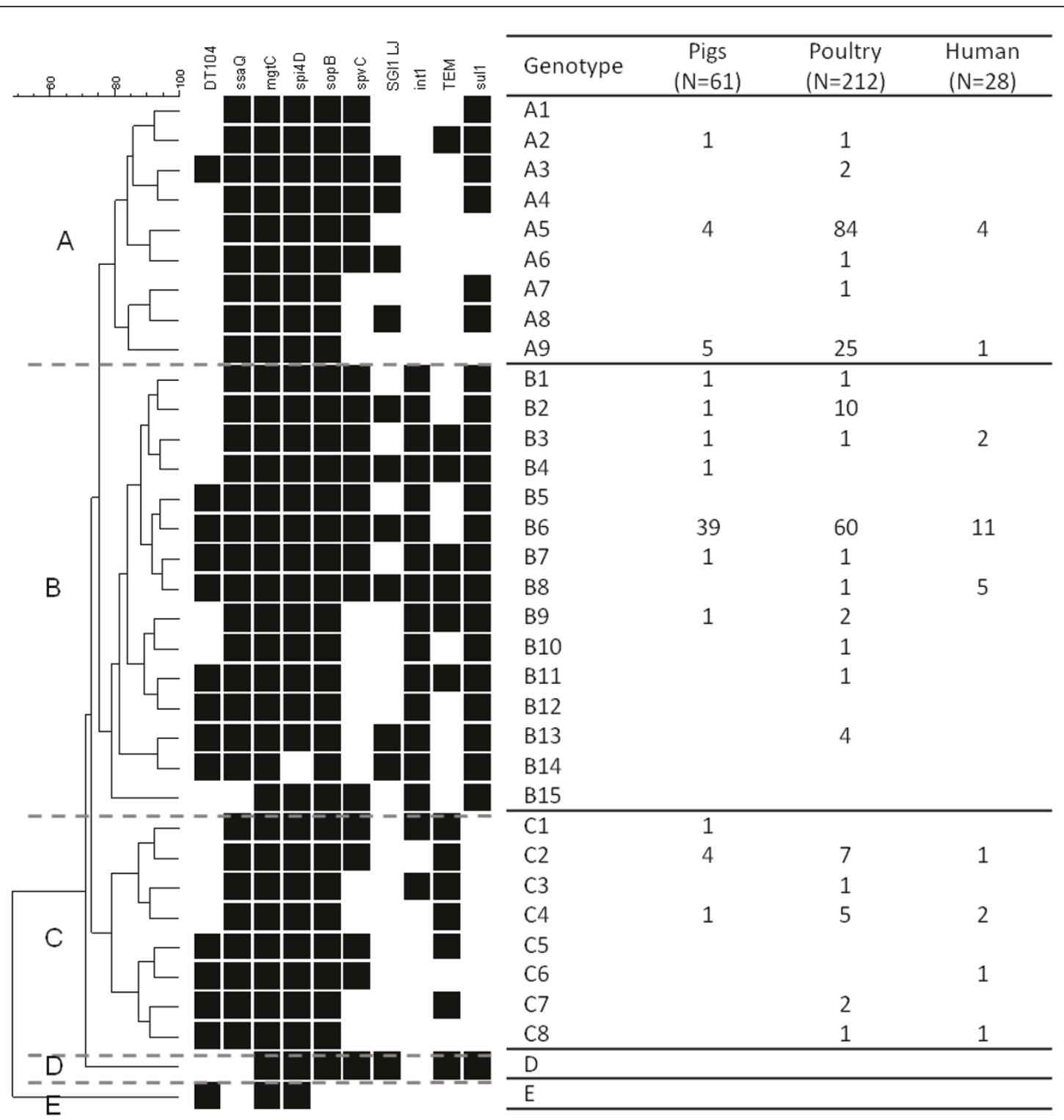

Figure 1 Genotype constructed with the Unweighted Pair Group Method using arithmetic Averages (UPGMA) on total investigated strains with strain distribution in the main isolation sources: poultry, pigs and human sources. A black box indicates the presence of the genotype's determinant gene. SGI1 LJ means "SGI1 Left Junction".

isolates [8]. Atypical profiles were detected in three strains, of which two were isolated from rabbit farms and feces. These two strains were negative for the spi_4D determinant located on SPI-4 and assigned to the B14 profile. The third atypical strain, isolated from an eagle, was negative for the ssaQ marker and assigned to the B15 profile (Figure 1).

Group $C$ included 49 strains divided into 8 genotypes that were found throughout the study period. All strains from Group C were negative for sul1 marker. They were also negative for intI1 and SGI1 left junction determinants except for two intI1 positive strains ( $\mathrm{C} 1$ and $\mathrm{C} 3$ profiles) isolated either from poultry or swine sources. Likewise, the DT104 marker was rare, observed in only $6.5 \%(\mathrm{n}=15)$ of Group C strains (Figure 1).

Two other minor groups-D and E-were identified, each composed of a single strain. Genotypes derived from these groups were considered atypical and uncommon. Some SPI virulence genes were missing: $s s a Q$ for the single Group D strain and both $m g t C$ and spi4D for the Group E strain. Group D and E strains were both recovered from environmental samples, suggesting the presence of such atypical isolates in ecosystem niches (Figure 1 and Table 2). 


\section{Association of the genetic markers from poultry, swine and human sources}

Strains from human and swine sources showed the three SGI1-associated markers (sul1, intI1 and SGI1 left junction) more frequently (57.1\% and $61.2 \%$ respectively) than those from poultry (35.4\%). For the three markers, statistical differences in percentages were observed between swine and poultry sources. Table 4 highlights the finding that poultry-source strains harbored all the investigated determinants less frequently, with the exception of SPI-associated genes.

In poultry sources (Figure 1 and Table 2), great diversity was observed as 21 different genotypes were identified and distributed over the main three groups, A, B and C. Six different genotypes identified in Group A accounted for $54 \%$ of the isolates ( $\mathrm{n}=114$ strains) mainly detected in two major genotypes A5 and A9. These two genotypes are those with low-marker patterns and account for more than half of the poultry strains. The frequently-encountered B6 and B2 genotypes were also detected for $33 \%$ of poultry strains out of a total of 10 different genotypes found in poultry sources The five Group C genotypes contained few poultry strains ( $\mathrm{n}=$ 16) compared to the total. In swine sources, the 61 strains were assigned to 13 genotypes (Figure 1 and Table 2). Most of the strains were categorized in seven Group B genotypes, especially B6 (64\%). A single strain of genotype $\mathrm{C} 1$ was detected in a swine source. All these Group B and C strains carried most of the tested determinants, especially the three SGI1-associated markers and the antimicrobial resistance determinants. Finally, the 28 strains from human sources were divided into nine different genotypes. The human strains shared the same genotypes as the poultry or swine strains whether in Group A, B or C, with the exception of a single strain that exhibited the C6 pattern never found in other sources. Sixty-four percent of Group B human strains carried the SGI1 determinant (64\%). Genotype B8, positive for all determinants was almost distributed in human source (5 out 6 strains).

\section{Discussion}

Over the past decade, serotype Typhimurium has been the most prevalent among Salmonella enterica subsp. enterica serotypes in human and animal sources worldwide. Furthermore, multiple-antibiotic-resistant strains have emerged, most often linked to phage type DT104. Many data regarding both the emergence and increase of phage type DT104 strains over the past years are available in some countries $[13,14]$. In contrast, no recent data are available regarding phage-type frequencies in French Typhimurium strains. A recent publication highlighted the lack of standardization of the phage-typing method within laboratories [15]. Detecting the phage type DT104 determinant using the GeneDisc ${ }^{\circledR}$ appears to be a valuable fast alternative method for monitoring isolates. Markers for SGI1 (left junction region), DT104 (16S-23S intergenic spacer region) and antibiotic-resistance (sul1) were tested in the GeneDisc ${ }^{\circledR}$ array developed here. Analysis of the results confirm the link between the three markers as previously described [16-18] and show that most of the tested Typhimurium collection carried all three markers simultaneously. Thus, of the 538 isolates tested, 210 (39\%) were assigned to genotype $\mathrm{B} 6$, the most common genotype of the 34 identified. The B6 genotype was characterized by the presence of all ten tested markers, except the $b l a_{\text {TEM }}$ gene. Other genotypes were closely related to B6, differing by only one or two markers. The majority of occurrences of $\mathrm{B} 6$ and $\mathrm{B} 8$ genotypes characterized by a high number of markers were host-specific. They have been observed in $64 \%, 60 \%$ and $57 \%$ of pig, cattle and human isolates respectively whereas only detected in $28 \%$ of poultry sources. The integrase of class 1 integron (intI1) is usually detected in isolates carrying SGI1. In our study, the intI1 determinant was only detected in $52 \%$ of the overall panel of isolates. In contrast, the two strains assigned to genotype B5 were positive for the DT104 marker and intI1 but negative for the SGI1 left junction and also exhibited a multi-drug-resistant phenotype. Another study also described this situation and concluded that class 1 integron gene cassettes should be detected in $48.5 \%$ of Salmonella isolates in which the SGI1 left junction is absent [8]. In another study, one DT104 strain [12] presented the same pattern associated with an ACSSuT pattern indicating the presence of an SGI1 variant in which molecular determinants could not be detected.

Our results revealed $36 \%$ bla $a_{\mathrm{TEM}}$-positive strains in human strains and $11 \%$ in animal strains. Beta-lactamase production continues to be the leading cause of resistance to beta-lactam antibiotics among gram-negative bacteria. Furthermore, there have been reports of an increased incidence and prevalence of extended-spectrum beta-lactamases (ESBLs) in recent years. The first ESBLs arose in the early $1980 \mathrm{~s}$ from mutation from widespread, broad-spectrum beta-lactamases such as TEM-1 or SHV-1. Monitoring the frequency of bla $a_{\mathrm{TEM}}$ in Salmonella is therefore a major public health concern. In our study, we identified 14 different genotypes harboring the bla $a_{\mathrm{TEM}}$ gene, representing $13 \%$ of isolates (68 isolates). The most frequent $b l a_{\text {TEM }}$ gene source was observed in human isolates (36\%), whereas it was detected in only $8 \%$ of environment-source strains and $11 \%$ of animal and food-product isolates. These results are consistent with a study performed on French Salmonella Typhimurium isolates to determine bla $a_{\text {TEM }}$ emergence in human and non-human sources which revealed 
the presence of $b l a_{\mathrm{TEM}}$ in $26 \%$ of human isolates and $23 \%$ of animal isolates $[19,20]$. Of the 14 different blaTEM genotypes, six of the Group B genotypes were always associated with the intI1 marker. The intI1 gene includes a site-specific recombination system capable of integrating and expressing genes contained in structures known as mobile gene cassettes. Integrons are described as a structure with high gene diversity in cassettes and a major reservoir of antibiotic-resistance genes, suggesting a broad role in adaptation during bacterial evolution and a major public health concern. In our study, the presence of intI1 from SGI1 in the absence of the SGI1 left junction was observed in nine Group B genotypes, two Group $C$ genotypes and never in Group A. Moreover, all the Group B genotypes harboring the bla $a_{\mathrm{TEM}}$ gene contained the sul1 determinant. Other such atypical strains were encountered during a European study on the molecular sub-typing of Salmonella genomic islands on a large collection of isolates from different countries. This last study highlighted a correlation between $s p \nu C$ positive strains and the presence of blaTEM not observed in the current study [8]. One of the main genotypes, A9, exhibited the four SPI-2 to -5 determinants in the absence of all the other targeted genes. A frequent, closely-related A5 genotype also harbored the same SPI pattern in addition to the plasmidassociated $s p v C$ determinant. Along with the B6 and C2 genotypes, these two major A5 and A9 genotypes were detected in all sources, particularly human, poultry and swine sources, which suggest that they are widespread throughout various niches. Salmonella plasmid-encoded virulence factors are a selective advantage to some $\mathrm{Sal}$ monella variants for colonizing new niches over the course of Salmonella evolution [21]. Our finding also indicates that Typhimurium strains could share common combinations of markers whatever their source. In contrast, some genotypes were unique to animal sources: A3, A6, B10, B11, B13 and C3 were unique to poultry sources; $B 4$ and $C 1$ were unique to swine sources. No genotypes were assigned exclusively to human strains, but the number of clinical strains tested was fairly low. Although the studied collection of strains was representative of the main animal and food sources, the Salmonella network collects Salmonella isolates on a voluntary basis. There may, therefore, have been some bias in the selected strains, especially for serotype Typhimurium mainly serotyped in other veterinary or food analysis laboratories. Moreover, the number of strains tested from each source was not evenly distributed. The high proportion of poultry isolates is due to European regulations in this production sector, leading to many surveillance and sampling programs with monitoring and official controls.
Studies suggest that Salmonella plasmid-encoded virulence factors are a selective advantage to some Salmonella variants for colonizing new niches over the course of Salmonella evolution [21].

\section{Conclusion}

The GeneDisc ${ }^{\circledR}$ macroarray presented in this study made it possible to easily explore variability of the ten relevant gene determinants within Typhimurium very quickly during a on-hour run. Based on the presence or absence of these markers, 34 different marker combinations (genotypes) were observed among the 538 studied isolates, recovered mainly from food, animal or human sources. Three major genotypes were defined, being observed in $75 \%$ of the studied strains. Although SPI determinants were almost always present, our findings show variation in the detection of other gene determinants, especially for the SGI1 specific determinants (left junction and intI1), sul1 and bla $a_{\mathrm{TEM}}$. In a microarraybased study on the characterization of Salmonella subspecies I isolates, most intra-serotype variation involved differences in only a few regions of the core genome [22]. This is the case for serotype Typhimurium. This study found major variation in the presence or absence of other gene determinants, as most of these determinants are plasmid- or transposon-mediated. These variations can be explained by intra-serotype horizontal gene exchanges that generate numerous genotype combinations. These horizontal gene transfer events may also occur between serotypes, as described in some studies demonstrating SGI1 lateral transfer from serotype Typhimurium to other serotypes [23,24]. This study highlighted variations in genotype frequencies according to source. Low-marker determinant genotypes were mostly detected in poultry sources, whereas high-marker determinant genotypes were observed in swine, cattle and human sources.

Serotyping cannot detect intra-serotype variation, so microarrays are currently most commonly used for comparative genome hybridization and gene expression studies. Nevertheless, although the high-density microarray-based approach has become more popular, these tools are limited by the availability of skilled personnel and require sophisticated equipment generally not available in routine surveillance laboratories [25,26]. This study demonstrates a very simple, specific, highthroughput, real-time multiplex PCR-based method that can determine genotypes for a preliminary analysis of Typhimurium intra-serotype diversity. Based on the same principle, the GeneDisc ${ }^{\circledR}$ system can be enhanced and extended to other pertinent targets and genes according to the issue to be addressed, such as serotype identification or emerging new resistance mechanisms. 


\section{Acknowledgements}

We would like to express our gratitude to Burkhard Malorny from the National Salmonella Reference Laboratory at the Federal Institute for Risk Assessment in Berlin, Germany, for providing negative control strain 0001041.

\section{Author details}

${ }^{1}$ French Agency for Food, Environmental and Occupational Health Safety (ANSES) Laboratory for Food Safety, 23 Avenue du Général de Gaulle, F94706 Maisons-Alfort Cedex, France. 'Laboratoire des Bactéries Pathogènes Entériques, Centre National de Référence des Salmonella, Institut Pasteur, 28 rue du Docteur Roux, 75724 Paris Cedex 15, France.

\section{Authors' contributions}

The macro-array was designed by PF, MB and AB. MB performed all the laboratory analyses. The results were analyzed and interpreted by MB, PF and AB. SAG gave special attention to the antimicrobial resistance aspect of data and the choice of control strains. FXW was responsible for the clinical isolates and performed some phage-typing assays. All the authors were involved in drafting or revising the manuscript. The authors read and approved the final manuscript.

Received: 10 November 2010 Accepted: 27 June 2011

Published: 27 June 2011

\section{References}

1. Anonymous: The Community Summary Report on trends and sources of zoonoses, zoonotic agents and food-borne outbreaks in the European Union in 2008. EFSA Journal 2010, 1496:288.

2. Swaminathan B, Gerner-Smidt P, Barrett T: Focus on Salmonella. Foodborne Pathog Dis 2006, 3(2):154-156

3. Hermans AP, Abee T, Zwietering MH, Aarts HJ: Identification of novel Salmonella enterica serovar Typhimurium DT104-specific prophage and nonprophage chromosomal sequences among serovar Typhimurium isolates by genomic subtractive hybridization. Appl Environ Microbiol 2005, 71(9):4979-4985.

4. Pritchett LC, Konkel ME, Gay JM, Besser TE: Identification of DT104 and U302 phage types among Salmonella enterica serotype Typhimurium isolates by PCR. J Clin Microbiol 2000, 38(9):3484-3488.

5. Ochman H, Soncini FC, Solomon F, Groisman EA: Identification of a pathogenicity island required for Salmonella survival in host cells. Proc Natl Acad Sci USA 1996, 93(15):7800-7804

6. Chu C, Chiu CH: Evolution of the virulence plasmids of non-typhoid Salmonella and its association with antimicrobial resistance. Microbes Infect 2006, 8(7):1931-1936.

7. Marcus SL, Brumell JH, Pfeifer CG, Finlay BB: Salmonella pathogenicity islands: big virulence in small packages. Microbes Infect 2000, 2(2):145-156.

8. Amar CF, Arnold C, Bankier A, Dear PH, Guerra B, Hopkins KL, Liebana E, Mevius DJ, Threlfall EJ: Real-time PCRs and fingerprinting assays for the detection and characterization of Salmonella Genomic Island-1 encoding multidrug resistance: application to 445 European isolates of Salmonella, Escherichia coli, Shigella, and Proteus. Microb Drug Resist 2008, 14(2):79-92.

9. Beutin $L$, Jahn $S$, Fach P: Evaluation of the 'GeneDisc' real-time PCR system for detection of enterohaemorrhagic Escherichia coli (EHEC) O26, 0103, 0111, 0145 and 0157 strains according to their virulence markers and their $\mathrm{O}$ - and $\mathrm{H}$-antigen-associated genes. J Appl Microbiol 2009, 106(4):1122-1132.

10. Bugarel $M$, Beutin $L$, Fach P: Low-density macroarray targeting non-locus of enterocyte effacement effectors (nle genes) and major virulence factors of Shiga toxin-producing Escherichia coli (STEC): a new approach for molecular risk assessment of STEC isolates. Appl Environ Microbiol 2010, 76(1):203-211.

11. Malorny B, Paccassoni E, Fach P, Bunge C, Martin A, Helmuth R: Diagnostic real-time PCR for detection of Salmonella in food. Appl Environ Microbiol 2004, 70(12):7046-7052.

12. Huehn S, La Ragione RM, Anjum M, Saunders M, Woodward MJ, Bunge C Helmuth R, Hauser E, Guerra B, Beutlich J, Brisabois A, Peters T, Svensson L, Madajczak G, Litrup E, Imre A, Herrera-Leon S, Mevius D, Newell DG, Malorny B: Virulotyping and Antimicrobial Resistance Typing of Salmonella enterica Serovars Relevant to Human Health in Europe. Foodborne Pathog Dis 2009.
13. Threlfall $E J$, Frost $J A$, Ward $L R$, Rowe $B$ : Epidemic in cattle and humans of Salmonella Typhimurium DT 104 with chromosomally integrated multiple drug resistance. Vet Rec 1994, 134(22):577.

14. Threlfall EJ, Skinner JA, Graham A, Ward LR, Smith HR: Resistance to ceftriaxone and cefotaxime in non-typhoidal Salmonella enterica in England and Wales, 1998-99. J Antimicrob Chemother 2000, 46(5):860-862.

15. Baggesen DL, Sorensen G, Nielsen EM, Wegener HC: Phage typing of Salmonella Typhimurium - is it still a useful tool for surveillance and outbreak investigation? Euro Surveill 15(4):19471.

16. Mulvey MR, Boyd DA, Olson AB, Doublet B, Cloeckaert A: The genetics of Salmonella genomic island 1. Microbes Infect 2006, 8(7):1915-1922.

17. Poppe C, Smart N, Khakhria R, Johnson W, Spika J, Prescott J: Salmonella Typhimurium DT104: a virulent and drug-resistant pathogen. Can Vet J 1998, 39(9):559-565.

18. Vo AT, van Duijkeren E, Gaastra W, Fluit AC: Antimicrobial resistance, class 1 integrons, and genomic island 1 in Salmonella isolates from Vietnam. PLoS One 5(2):e9440.

19. Casin I, Breuil J, Brisabois A, Moury F, Grimont F, Collatz E: Multidrugresistant human and animal Salmonella Typhimurium isolates in France belong predominantly to a DT104 clone with the chromosome- and integron-encoded beta-lactamase PSE-1. J Infect Dis 1999, 179(5):1173-1182.

20. Weill FX, Guesnier F, Guibert V, Timinouni M, Demartin M, Polomack L, Grimont PA: Multidrug resistance in Salmonella enterica serotype Typhimurium from humans in France (1993 to 2003). J Clin Microbiol 2006, 44(3):700-708.

21. Fierer J, Guiney DG: Diverse virulence traits underlying different clinical outcomes of Salmonella infection. J Clin Invest 2001, 107(7):775-780.

22. Porwollik S, Boyd EF, Choy C, Cheng P, Florea L, Proctor E, McClelland M: Characterization of Salmonella enterica subspecies I genovars by use of microarrays. J Bacteriol 2004, 186(17):5883-5898.

23. Cloeckaert A, Schwarz S: Molecular characterization, spread and evolution of multidrug resistance in Salmonella enterica Typhimurium DT104. Vet Res (Paris) 2001, 32(3-4):301-310.

24. Doublet B, Boyd D, Mulvey MR, Cloeckaert A: The Salmonella genomic island 1 is an integrative mobilizable element. Mol Microbiol 2005, 55(6):1911-1924

25. Miller MB, Tang YW: Basic concepts of microarrays and potential applications in clinical microbiology. Clin Microbiol Rev 2009, 22(4):611-633.

26. Scaria J, Palaniappan RU, Chiu D, Phan JA, Ponnala L, McDonough P, Grohn YT, Porwollik S, McClelland M, Chiou CS, Chu C, Chang YF: Microarray for molecular typing of Salmonella enterica serovars. Mol Cell Probes 2008, 22(4):238-243.

doi:10.1186/1471-2180-11-151

Cite this article as: Bugarel et al:: A multiplex real-time PCR assay targeting virulence and resistance genes in Salmonella enterica serotype Typhimurium. BMC Microbiology 2011 11:151.

\section{Submit your next manuscript to BioMed Central and take full advantage of:}

- Convenient online submission

- Thorough peer review

- No space constraints or color figure charges

- Immediate publication on acceptance

- Inclusion in PubMed, CAS, Scopus and Google Scholar

- Research which is freely available for redistribution

Submit your manuscript at www.biomedcentral.com/submit
C BioMed Central 